\title{
Droplet activation of moderately surface active organic aerosol predicted with six approaches to surface activity
}

\author{
Sampo Vepsäläinen ${ }^{1}$, Silvia M. Calderón ${ }^{1,2}$, Jussi Malila ${ }^{1}$, and Nønne L. Prisle ${ }^{1,3}$ \\ ${ }^{1}$ Nano and Molecular Systems Research Unit, University of Oulu, P.O. Box 3000, FI-90014, Oulu, Finland \\ ${ }^{2}$ Finnish Meteorological Institute, P.O. Box 1627, FI-70211, Kuopio, Finland \\ ${ }^{3}$ Center for Atmospheric Research, University of Oulu, P.O. Box 4500, FI-90014, Oulu, Finland
}

Correspondence: Nønne L.Prisle (nonne.prisle@oulu.fi)

\begin{abstract}
Surface active compounds (surfactants) found in atmospheric aerosols can decrease droplet surface tension as they adsorb to the droplet surfaces simultaneously depleting the droplet bulk. These processes may influence the activation properties of aerosols into cloud droplets and investigation of their role in cloud microphysics has been ongoing for decades. In this study, we have used six different approaches documented in the literature to represent surface activity in Köhler calculations predicting cloud droplet activation properties for particles consisting of one of three different moderately surface active organics mixed with ammonium sulphate in different ratios. We find that the different models predict comparable activation properties at small organic mass fractions in the dry particles for all three moderately surface active organics tested, even with large differences in the predicted degree of bulk-to-surface partitioning of the surface active component. However, differences between the models regarding both the predicted critical diameter and supersaturation for the same dry particle size increase with the organic fraction in the particles. Comparison with available experimental data shows that assuming complete bulkto-surface partitioning of the organic component (total depletion of the bulk) along the full droplet growth curve does not adequately represent the activation properties of particles with high moderate surfactant mass fractions. Accounting for the surface tension depression mitigates some of the effect. Models that include the possibility for partial bulk-to-surface partitioning yield comparable results to the experimental data, even at high organic mass fractions in the particles. The study highlights the need for using thermodynamically consistent model frameworks to treat surface activity of atmospheric aerosols and for firm experimental validation of model predictions across a wide range of states relevant to the atmosphere.
\end{abstract}

\section{Introduction}

The effect of atmospheric aerosols on the climate is still among the largest uncertainties to estimates and interpretations of the Earth's changing energy budget (IPCC, 2013; Seinfeld et al., 2016). An aerosol population can be composed of dozens of inorganic salts mixed with hundreds of organic species. Single-particle measurements have shown mixtures of compounds from primary sources, such as soot, dust and organic carbon, mixed with sulfate, nitrate and oxidized organics from secondary 
aerosol formation (e.g. Li and Shao, 2009; Gieré and Querol, 2010). Surface active organic species (surfactants) are frequently found in atmospheric aerosols from many different regions and environments (e.g. Gérard et al., 2016; Petters and Petters, 2016; Nozière et al., 2017; Kroflič et al., 2018; Gérard et al., 2019). In liquid aerosol mixtures, such as aqueous droplets, surfactants can adsorb at the interfaces, lowering the surface tension and inducing concentration gradients between the droplet surface and bulk compartments.

The various effects of surface activity for cloud microphysics have been investigated for decades, starting with Hänel (1976), who discussed the importance of possible surface tension deviations from the value for pure water on the equilibrium equivalent size of droplets, also noting how lowered surface tension values may lead to a decrease in critical supersaturation and an increase in critical droplet size. Surfactants could therefore potentially modify the cloud activation properties of aerosols by lowering the surface tension at the air-droplet interface. Shulman et al. (1996) presented model calculations demonstrating this effect and showed that reduced surface tension of aqueous droplets can affect the shape of the Köhler growth curves (Köhler, 1936), lowering the required critical supersaturation for cloud droplet activation. Facchini et al. (1999) soon after measured the surface tension of atmospheric bulk samples, noting a significant surface tension depression at total organic concentrations considered to be representative of activating droplets, and further demonstrated that similar reductions in surface tension of activating cloud droplets could translate to a significant change in the cloud radiative forcing on a global scale. Facchini et al. (2000) then confirmed that organic surfactants are indeed present in atmospheric aerosol, supporting the ability of cloud condensation nuclei $(\mathrm{CCN})$ to reduce the surface tension of atmospheric droplets.

These works did not consider that surface adsorption and the resulting concentration gradient between surface and bulk phases can also lead to significant depletion of the bulk phase in microscopic and submicron droplets typically involved in cloud droplet activation, due to their large surface area-to-bulk volume ratios (e.g. Prisle et al., 2010; Bzdek et al., 2020; Lin et al., 2020). This distribution of surfactant mass between the surface and bulk of a solution is often referred to as the bulkto-surface partitioning. In microscopic droplet solutions, the partitioning can be strongly in favor of the surface, whereas the bulk of a macroscopic solution is essentially an infinite reservoir and concentrations are unaffected by surface adsorption (e.g. Prisle et al., 2010; Lin et al., 2018, 2020). The effect of surfactant bulk-surface partitioning was first considered by Li et al. (1998), who used a calculation scheme where droplet bulk depletion was taken into account in the droplet surface tension and therefore the shape of the Köhler growth curve. Sorjamaa et al. (2004) then proposed that similar partitioning effects must be included also in the solute (Raoult) effect of the droplet vapor equilibrium.

They presented thermodynamic predictions showing that partitioning of the surfactant from the droplet bulk to the surface can limit the amount of dissolved solute and, as a result, reduce hygroscopic water uptake (Sorjamaa et al., 2004). The studies of Li et al. (1998) and Sorjamaa et al. (2004) focused on droplets comprising a model surfactant sodium dodecyl sulfate and suggested that the isolated consideration of surface tension depression in cloud droplet activation without accounting for the surfactant partitioning effect on bulk hygroscopicity can lead to exaggerated potential of cloud droplet nuclei (CCN) activation. This was later demonstrated both experimentally and in thermodynamic model calculations for droplets comprising a series of atmospherically relevant fatty acid salts and systematically across their mixtures with sodium chloride (Prisle et al., 2008, 2010). 
Experimental evidence for the role of surface activity in activating droplets has yet to form a consistent picture. The predicted bulk-surface partitioning effects were only recently verified for finite-sized droplets suspended in the air (Bzdek et al., 2020). The analysis of experimentally determined CCN activity of surface active aerosols is complicated by the interdependent effects on surface tension and solute effects in finite systems (Prisle et al., 2010; Lin et al., 2020), which cannot readily be deconvolved in experiments with microscopic or submicron droplets. Many studies have focused on estimating the surface tension depression of activating droplets (e.g. Padró et al., 2010; Giordano et al., 2013). However, Prisle et al. (2008, 2010) found that experimentally observed CCN activation of straight chain fatty acid sodium salts was consistent with only very modest surface tension reduction in droplets, compared to pure water. These results imply that using pure water surface tension may give more realistic predictions of CCN activity for organic aerosol in large scale simulations than surface tension calculated without consideration of bulk-surface partitioning in droplets (Prisle et al., 2012b), but such an approximation may not be generally applicable (e.g. Nozière et al., 2014; Petters and Petters, 2016; Lowe et al., 2019).

Fatty acids and their salts are a major class of organic compounds identified in atmospheric aerosols (e.g. Mochida et al., 2002, 2007; Cheng et al., 2004; Li and Yu, 2005; Forestieri et al., 2018) and often are relatively strong surfactants (see e.g. Prisle et al. $(2008,2010)$ and references therein), but also surfactants of moderate strength are abundantly present in the atmosphere. In microscopic droplets, strong surfactants are predicted to be strongly depleted from the bulk phase due to bulk-surface partitioning, leading to modest effective hygroscopicity of the surface active component, while at the same time, the finite amount of surface active material is still not sufficient to significantly reduce droplet surface tension (Prisle et al., 2008, 2010, 2011; Lin et al., 2020; Bzdek et al., 2020). This behavior may however be a limiting case and not representative across the whole range of surfactant strength and other molecular properties found in the atmosphere. The partitioning behavior of moderate surfactants may be more complex and dependent on droplet concentration and size (governing the surface areato-bulk volume ratio). It has been shown that partitioning between droplet bulk and surface can affect activation properties of surface active aerosol: Enhancement of hygroscopicity has been reported from surface tension effects for organosulfate products (Hansen et al., 2015), secondary organic aerosol containing dicarboxylic acids (Ruehl et al., 2016), marine primary organics (Ovadnevaite et al., 2017), and pollen extracts (Prisle et al., 2019). Therefore, thermodynamically consistent bulksurface partitioning models are needed to fully represent surfactant properties (strength) and mixing states in such droplet systems.

Several models have been developed to be used with Köhler theory to calculate bulk-surface partitioning of surface active components and the resulting effects in growing droplets, including the Gibbs surface approach by Sorjamaa et al. (2004); Prisle et al. $(2008,2010)$, the molecular monolayer surface model by Malila and Prisle (2018), the liquid-liquid phase separation (LLPS) approach with possible partial surface coverage by Ovadnevaite et al. (2017) and the compressed film surface model by Ruehl et al. (2016). Each of these models rely on a unique set of assumptions and requirements for application. In addition, simplified models, emulating the results of more comprehensive frameworks (Prisle et al., 2011), with further simplifying assumptions (Ovadnevaite et al., 2017), derived as analytical approximations to ease the computational load (Topping, 2010; Raatikainen and Laaksonen, 2011) have also all been employed. A more extensive overview of different bulk-surface partitioning approaches is given by Malila and Prisle (2018). Many of the models have been shown to agree well with exper- 
imentally observed CCN activity for selected model aerosol systems (e.g. Ruehl et al., 2016; Lin et al., 2018; Davies et al., 2019). A few studies have presented the results from different models for the same droplet systems. Lin et al. (2018) compared the models of Prisle et al. (2010), Prisle and Mølgaard (2018) and Malila and Prisle (2018) for multiple droplet systems comprising of succinic acid, sodium dodecyl sulphated (SDS) and Nordic Aquatic Fulvic Acid (NAFA) mixed with natrium chloride as well as pollenkitts mixed with ammonium sulphate. Davies et al. (2019) used the model of Ruehl et al. (2016) and different variations of the models presented in Ovadnevaite et al. (2017) for a system of ammonium sulphate particles coated with suberic acid. However, to the best of our knowledge, a comprehensive systematic comparison between multiple partitioning models has not previously been done.

In this study, we have used the thermodynamic and simplified partitioning models of Prisle et al. (2010), Prisle et al. (2011), Malila and Prisle (2018), Ruehl et al. (2016), Ovadnevaite et al. (2017), as well as a general bulk solution model, all implemented into the same Köhler model framework. Each of the models are used to calculate Köhler curves for particles consisting of a moderate organic surfactant mixed with ammonium sulphate. Moderate organic surfactants are represented by dicarboxylic acids due to their immediate atmospheric relevance (e.g. Shulman et al., 1996; Hori et al., 2003) and abundance (e.g. Khwaja, 1995; Mochida et al., 2007; Jung et al., 2010). We quantify surfactant strength similarly to Prisle et al. (2010, 2011) as the surface tension reduction from that of pure water at a given surfactant bulk phase concentration. To reduce the surface tension of water in an aqueous bulk solution by $10 \%$ at $298.15 \mathrm{~K}$, the mole fraction of malonic, succinic and glutaric acids in the solution estimated from a fit (Hyvärinen et al., 2006) to be about $0.061,0.017$ and 0.0070 respectively. In addition, the dicarboxylic acids used for this study can reduce surface tension to roughly $50 \mathrm{mN} \mathrm{m}^{-1}$ at most in large enough concentrations (Hyvärinen et al., 2006; Booth et al., 2009). Stronger surfactants, such as fatty acid salts, can reduce surface tension to $20-30 \mathrm{mN} \mathrm{m}^{-1}$ at most (Prisle et al., 2010). The thermodynamic properties required for the simulations are relatively well constrained for dicarboxylic acids (e.g. Booth et al., 2009; Hyvärinen et al., 2006; Ruehl et al., 2016). We compare the Köhler growth curves predicted with the different models to investigate impacts of the significant differences between the model assumptions and the expected high sensitivity of the partitioning equilibrium for the moderately strong surfactant to the assumed droplet state. A separate companion study is currently in preparation, comparing predictions with the same models for particles comprising stronger surfactants.

\section{Theory \& Methods}

Six different modeling approaches are used to estimate the possible surfactant effects in Köhler calculations of droplet growth and CCN activation. Descriptions of the different model calculations are presented in the following sections. Each of the bulksurface partitioning models were implemented into the same Köhler model framework running in MATLAB (2019, 2020). Models that were not previously developed by Prisle and co-workers, were built in MATLAB $(2019,2020)$ with the information provided in the presenting publications and by the authors in personal communication. Köhler growth curves were simulated for dry particles consisting of one of the dicarboxylic acids, malonic acid, succinic acid or glutaric acid, mixed with ammonium 
sulphate in mass fractions ranging from 0.2-0.95. In all cases, droplet activation is evaluated based on the maximum value of the calculated Köhler curve.

\subsection{Köhler theory}

Cloud droplets form in the atmosphere when water vapor condenses on the surfaces of aerosol particles. The Köhler equation (Köhler, 1936) describes the process, relating the equilibrium water vapor saturation ratio $(S)$ over a spherical solution droplet to its diameter $(d)$ as

$S \equiv \frac{p_{w}}{p_{w}^{0}}=a_{w} \exp \left(\frac{4 \bar{v}_{w} \sigma}{R T d}\right)$

where $p_{w}$ is the equilibrium partial pressure of water over the solution droplet, $p_{w}^{0}$ is the saturation vapor pressure over a flat surface of pure water, $a_{w}$ is the droplet solution water activity, $\bar{v}_{w}=M_{w} / \rho_{w}$ is the molar volume of water, $\sigma$ is the droplet surface tension, $R$ is the universal gas constant, and $T$ is the temperature in Kelvin. The water vapor supersaturation is generally defined as $S S=(S-1) \cdot 100 \%$ and droplet activation is determined in terms of the critical supersaturation $\left(S S_{c}\right)$ or critical saturation ratio $\left(S_{c}\right)$, corresponding to the maximum value of the Köhler curve described by Eq. (1). Köhler theory is used in all cases in this study to describe the formation of cloud droplets, but the treatment of bulk-surface partitioning of surface active species and the resulting droplet water activity and surface tension varies between the models.

All the Köhler calculations are initiated by defining a dry particle size and composition which determines the total amount of solute in the growing droplets. For each dry particle size, the total amounts of ammonium sulphate salt and organic molecules are calculated based on their pure solid phase densities and relative mass fractions in the particle, with the assumption of spherical dry particles and additive solid phase volumes in all cases. For each droplet size along the Köhler curve for a given dry particle, the total amount of water in the droplet phase is estimated from the droplet size via model specific methods, listed in Table 1. Here, iterative calculation refers to determining the total amount of water $\left(n_{w}^{T}\right)$ based on mass conservation using the ternary mixture density while additive calculation refers to the assumption of additive volumes of the dry particle and the condensed water (Hänel, 1976) and is calculated by subtracting the dry particle volume from the total droplet volume. The equations for calculating the total amounts of salt, organic and water are presented in the supplement section S2.2.

The droplet solution is a ternary water-inorganic-organic mixture. As each droplet grows, the surface area-to-bulk volume decreases, which in turn affects the bulk-surface partitioning of surface active species (Prisle et al., 2010; Bzdek et al., 2020). The different partitioning models compared in this work make different assumptions regarding the partitioning of droplet components. While some consider only partitioning of the surface active species into a purely organic surface phase (Prisle et al., 2011; Ruehl et al., 2016; Ovadnevaite et al., 2017), others evaluate the full composition of both droplet surface and bulk phases (Prisle et al., 2010; Malila and Prisle, 2018). Table 1 lists how the different models calculate the initial amount of water, the water activity, the surface tension of the droplets and what compounds reside in the droplet surface and bulk. 


\subsection{Gibbs adsorption partitioning model}

In Gibbs surface thermodynamics, the gas-liquid interface is assumed to be an infinitely thin 2-dimensional surface called the Gibbs dividing surface, the location of which may vary depending on specific assumptions made for the system. The modeled idealized system is energetically and mechanically equivalent to the real system it represents (Defay and Prigogine, 1966). Several bulk-surface partitioning models for droplets have been developed based on Gibbs surface thermodynamics (e.g. Li et al., 1998; Sorjamaa et al., 2004; Prisle et al., 2010; Topping, 2010; Raatikainen and Laaksonen, 2011; Petters and Kreidenweis, 2013; Prisle and Mølgaard, 2018) but the assumptions related to the position of the dividing surface and the method of solving the Gibbs adsorption equation (Gibbs, 1878) differ between the models.

In the model applied here (Prisle et al., 2010), the position of the Gibbs dividing surface is determined such that the bulkphase volume $\left(V^{B}\right)$ is equal to the total (equimolar) droplet volume $\left(V^{T}\right)$ of all droplet components $j$. Compounds adsorbed to the surface are assumed to not contribute to the total droplet volume, whence a positive surface volume of one compound (surfactant) must be balanced by depletion of other compounds (water and salt) from the surface. Sorjamaa et al. (2004) combined the adsorption equation with the Gibbs—-Duhem equation for the droplet bulk, resulting in

$\sum_{j} n_{j}^{T} k T \frac{d \ln \left(a_{j}^{B}\right)}{d n_{\mathrm{org}}^{B}}+A \frac{d \sigma}{d n_{\mathrm{org}}^{B}}=0$,

where $n_{j}^{T}$ is the total amount of species $j$ in the droplet solution, $k$ is the Boltzmann constant, $n_{\mathrm{org}}^{B}$ is the number of surfactant molecules in the droplet bulk, $a_{j}^{B}$ is the activity of $j$ in the droplet bulk solution, $A$ is the spherical droplet surface area and $\sigma$ is the droplet surface tension, given as function of bulk-phase composition. Equation (2) is solved iteratively for the bulk composition with the boundary condition that the molar ratio of water and salt is the same in the bulk and surface phases, such that the only adsorbing species is the surfactant. In addition, we assume volume additivity (such that the droplet diameter is given by the sum of individual pure component molar volumes) and mass conservation $\left(n_{j}^{T}=n_{j}^{S}+n_{j}^{B}\right)$ inside the droplet (Prisle, 2006). The assumption of additive volumes is employed for calculating the total amount of water in the droplets at each droplet size along the Köhler growth curve. The calculation details relating to the total amount of water are given in supplement section S2.2.

\subsection{Simple complete partitioning model}

The simple model of Prisle et al. (2011) was developed to emulate the more complex Gibbs model of Prisle et al. (2010) specifically for predictions of $S S_{c}$. It approximates organic partitioning by simply assuming that all surface-active organics are partitioned to the droplet surface into an insoluble layer. The surfactant solute therefore does not affect the water activity or surface tension of the aqueous droplet solution at the point of activation. This was shown to give very good representation of both the comprehensive model predictions and experimental results for droplet activation presented by Sorjamaa et al. (2004) and Prisle et al. $(2008,2010)$. The amount of surfactant in the droplet bulk is consequently vanishing $\left(n_{\mathrm{org}}^{B}=0\right)$, whereas neither salt nor water are present in the droplet surface. The total amount of water in the droplet is calculated assuming volume additivity of water and dry particle components. The surface tension of the droplet solution is assumed equal to that of pure 
water and therefore invariant with concentrations of both salt and surfactant in the droplet. Predictions with the comprehensive Gibbs partitioning model (Prisle et al., 2010) shows that this perhaps counter-intuitive condition is closely met in many droplet states, where the very surface area-to-bulk volume ratios of microscopic droplets result in insufficient surface concentrations to significantly reduce surface tension, despite nearly all surface active material in the finite-sized droplets being partitioned to the surface (Prisle et al., 2010, 2011; Bzdek et al., 2020).

\subsection{Compressed film surface model}

The partitioning model of Ruehl et al. (2016) describes the surface as a compressed film (Jura and Harkins, 1946) and assumes phase separation in a droplet between the pure organic surface layer and droplet bulk. This framework is conceptually similar to the earlier van der Waals model of Ruehl and Wilson (2014), but applies different surface equations of state. Similarly to the Gibbs adsorption and simple complete partitioning models, only the organic partitioning is considered. The partitioning of surface active organic is assumed to take place into a 2-dimensional compressed film. As the droplet grows, the surface thickness decreases and eventually reaches a single monolayer, at which point the surface undergoes a phase transition to a non-interacting "gaseous" state and the surface tension reaches that of water (Forestieri et al., 2018). Typically, the compressed film model predicts activation to take place for droplets in this state (Ruehl et al., 2016).

Droplet growth and surfactant partitioning is treated at two different levels of iteration in the compressed film model. At the outer level, the equilibrium relative humidity (RH) is determined iteratively for each droplet diameter $d$ via Eq. (1). Water activity of the droplet bulk is calculated as the corrected mole fraction at each step of the iteration. The initially dry particles in the compressed film model are assumed to be composed of a salt core coated by a layer of organic, where both the diameters of the salt seed $\left(D_{\text {seed }}\right)$ and coated particle $\left(D_{p}\right)$ are known. The total amounts of all components in the droplet phase are calculated with the assumption of volume additivity, both between the different components in the dry particle, and between the dry particle and water. The calculations use a different set of relations for the total amounts of salt, organic and water than the other partitioning models used in this work, in particular relating the salt and organic solid state molar volumes to the different diameters of the seed, coated and droplet diameters. For more information, see the Ruehl et al. (2016) supplement.

The inner level iteration takes place at the beginning of the outer level and calculates the fraction of organic molecules adsorbed to the droplet surface, $f_{\text {surf }}$, using the isotherm for equation of state (EoS) of the compressed film model

$\ln \left(\frac{C_{\mathrm{bulk}}}{C_{0}}\right)=\frac{\left(A_{0}^{2}-A^{2}\right) m_{\sigma} N_{A}}{2 R T}$,

where $C_{0}$ is the bulk solution concentration at the 2-dimensional phase transition, $C_{\mathrm{bulk}}$ is the bulk solution concentration, $A_{0}$ is the critical molecular area, $m_{\sigma}$ accounts for the interaction between surfactants at the interface and $N_{A}$ is Avogadro number.

215 For each value of $f_{\text {surf }}$, values for $C_{\text {bulk }}$ and $A$ are calculated as

$C_{\mathrm{bulk}}=\frac{\left(1-f_{\mathrm{surf}}\right)\left(D_{p}^{3}-D_{\mathrm{seed}}^{3}\right) \bar{v}_{w}}{d^{3} \bar{v}_{\text {org }}}$

and

$A=\frac{6 \bar{v}_{\text {org }} d^{2}}{f_{\text {surf }}\left(D_{p}^{3}-D_{\text {seed }}^{3}\right) N_{A}}$. 
The droplet surface tension is calculated via an EoS that parameterizes $\sigma$ in terms of molecular area $(A)$ and therefore relates $\sigma$ to the concentration of organics at the surface as

$\sigma=\min \left(\sigma_{w}, \max \left(\sigma_{w}-\left(A_{0}-A\right) m_{\sigma}, \sigma_{\min }\right)\right)$,

where $\sigma_{\min }$ is a lower limit imposed on the surface tension.

The model parameters $A_{0}, C_{0}, m_{\sigma}$ and $\sigma_{\min }$ are acquired through a separate fitting to experimental observations of $(d, \mathrm{RH})$ using Eq. (1) in the range of droplet sizes before droplet activation (the rising part of the Köhler curve) at one organic fraction (Ruehl et al., 2016), or across several organic fractions at a fixed value of RH (Forestieri et al., 2018). The values used in this work were obtained from Ruehl et al. (2016) and are provided in the supplement. These parameters are assumed to be compound specific physical constants and therefore to not be sensitive to seed or coated diameters or droplet dilution state, such that they can be applied across a range of organic fractions.

\subsection{Partial organic film model}

The partial organic film model used here is similar to the AIOMFAC-based simplified organic film model of Ovadnevaite et al. (2017), where all organic is assumed to reside in an insoluble surface film adsorbed on an aqueous salt-rich bulk phase similar to the assumption of Prisle et al. (2011) (permanent organic/inorganic phase separation). The full AIOMFAC-based thermodynamic equilibrium model of Ovadnevaite et al. (2017) predicts possible liquid-liquid phase separation (LLPS), phase compositions and volumes, to describe droplets where partial surface coverage of a hygroscopic particle core ( $\alpha$, bulk) by a organic rich phase ( $\beta$, surface) is possible. In the model employed for this study, no water is present in the film, and it is assumed to coat the bulk entirely until a minimum surface thickness $\left(\delta_{\text {org }}\right)$ is reached and the organic film breaks, only partially covering the core phase for larger droplets. According to Ovadnevaite et al. (2017), the value roughly corresponds to an average molecular monolayer thickness, $\delta_{\text {org }}=0.16-0.3 \mathrm{~nm}$, which is similar to the lengths scale of one to two covalent carbon-carbon bonds or van der Waals radii of carbon and oxygen atoms (Bondi, 1964). For the simulations in this study, $\delta_{\text {org }}$ was set equal to the values given by the molecular surface monolayer model of Malila and Prisle (2018), which here predicts values between $0.39-0.67 \mathrm{~nm}$, depending on the droplet size and the specific organic compound (figure in the supplement section S1.3).

In the version of the model implemented here, water activity in the droplet bulk was calculated using a fit to AIOMFAC (Zuend et al., 2008, 2011; AIOMFAC-web) predictions as a function of salt mole fraction in the concentration range relevant for the growing droplets. The fit can be found in the supplement section S2.3. The initial amounts of each compound in the droplets are determined via volume additivity, same as in the simple complete partitioning model of Prisle et al. (2011).

Following notation established in this study, we refer to the phase $\alpha$ as the bulk $(B)$, and the phase $\beta$ as the surface $(S)$. The model of Ovadnevaite et al. (2017) calculates the surface tension of an individual liquid phase as a volume fraction- weighted mean of the pure-component surface tension values $\left(\sigma_{j}\right)$. For phase the bulk phase

$\sigma^{B}=\sum_{j} \varphi_{j}^{B} \sigma_{j}$, 
where $\varphi_{j}^{B}$ is the volume fraction of component $j$ in the bulk phase $\left(\sum_{j} \varphi_{j}^{B}=1\right)$. The surface coverage parameter $c_{S}$ is defined as

$$
c_{S}=\min \left(\frac{V^{S}}{V^{\delta}}, 1\right)
$$

and determines whether the bulk is completely $\left(c_{S}=1\right)$ or partially $\left(c_{S}<1\right)$ covered by the organic film. Here, $V^{S}$ is the volume of the surface phase at diameter $d$ and $V^{\delta}$ is the corresponding volume of a spherical shell of thickness $\delta_{\text {org. The }}$ effective surface tension of the droplet is calculated as the surface area weighted mean of the surface tensions from both phases as

$\sigma=\left(1-c_{S}\right) \sigma^{B}+c_{S} \sigma^{S}$.

\subsection{Monolayer surface model}

The molecular monolayer surface model of Malila and Prisle (2018) divides an aqueous droplet into a surface monolayer of thickness $\delta$ and droplet bulk with diameter $d-2 \delta$. The monolayer is described as a pseudo-liquid phase with a distinct composition from the droplet bulk and the monolayer composition is evaluated in terms of total amount of molecules for all components in the droplet, not just the surfactant. For each species $j$, the partitioning between the bulk and surface phases is calculated iteratively from an extension of the Laaksonen-Kulmala equation (Laaksonen and Kulmala, 1991) relating the droplet surface tension $\sigma$ (as a function of bulk composition) to the surface composition as

$265 \sigma\left(x^{B}, T\right)=\frac{\sum_{j} \sigma_{j} v_{j} x_{j}^{S}}{\sum_{j} v_{j} x_{j}^{S}}$.

In Eq. (10), $v_{j}$ is the liquid (i.e. droplet surface) phase molecular volume, $\sigma_{j}$ the surface tension, and $x_{j}^{S}$ and $x_{j}^{B}$ the droplet surface and bulk mole fractions, respectively, all for component $j$. The condition of mass conservation $\left(n_{j}^{T}=n_{j}^{S}+n_{j}^{B}\right)$ is imposed on the calculation for each compound $j$. The total amount of water is determined iteratively at each droplet diameter by assuming mass conservation of all compounds in the droplet, together with the ternary mixture density, which is here a function of the droplet composition. Details of calculating the total amount of water are given in section S2.2 of the supplement. The thickness of the surface molecular monolayer is calculated as

$\delta=\left(\frac{\pi}{6} \sum_{j} v_{j} x_{j}^{S}\right)^{1 / 3}$.

\subsection{The bulk solution model}

Simulations with the different partitioning models described are compared to a model representing the droplet as a bulk solution, neglecting effects of surfactant partitioning between the droplet bulk and surface. All surfactant mass is assumed to be even distributed in the bulk phase, which is equivalent in volume to the whole droplet (no separate surface phase). In the implementation used in this work, the amount of water in the droplet is solved iteratively from the ternary solution density, similarly to the monolayer model (Malila and Prisle, 2018). The droplet surface tension is evaluated from a fit to the ternary data reported by Booth et al. (2009). Details of the fit are provided in the supplement section S3.1. 
Table 1. Methods of calculating the total amount of water $\left(n_{w}^{T}\right)$, the water activity $\left(a_{w}\right)$, the surface tension $(\sigma)$ and the composition of droplet surface and bulk, when they differ from the pure surfactant, for the different models. Details of the activity and surface tension equations are given in the supplement.

\begin{tabular}{lccccc}
\hline Model & $n_{w}^{T}$ & $a_{w}$ & $\sigma$ & Surface comp & Bulk comp \\
\hline $\begin{array}{l}\text { Monolayer } \\
\text { Gibbs }\end{array}$ & Iterative & Ideal & Fit to data $^{a}$ & org, salt, water & org, salt, water \\
Simple & Additive & Ideal & Fit to data $^{a}$ & org, salt, water ${ }^{b}$ & org, salt, water \\
Bulk solution & Additive & Fit to data ${ }^{c}$ & $\sigma_{w}$ & org & salt, water \\
Compressed film & Iterative & Ideal & Fit to data & - & org, salt, water \\
Partial organic film & Additive & Ideal & Eq. (6) & org & salt, water, org $\left(S<S_{c}\right)^{d}$ \\
\hline${ }^{a}$ Fit into the data of Booth et al. (2009) at 294.15 K. Fit details are in the supplement. ${ }^{b}$ Salt and water depletion from the surface balance the \\
organic partitioning. ${ }^{c}$ Prisle (2006) ${ }^{d}$ Typically all organic has partitioned to the surface at activation. ${ }^{e}$ Fit into AIOMFAC-web calculations.
\end{tabular}

Table 2. The molar masses $(M)$, liquid and solid densities $\left(\rho_{L}\right.$ and $\left.\rho_{S}\right)$ and surface tensions $(\sigma)$ of the different droplet components at 298.15 $\mathrm{K}$, unless stated otherwise.

\begin{tabular}{lcccc}
\hline Compound & $M\left(\mathrm{~g} \mathrm{~mol}^{-1}\right)$ & $\rho_{L}\left(\mathrm{~kg} \mathrm{~m}^{-3}\right)$ & $\rho_{S}\left(\mathrm{~kg} \mathrm{~m}^{-3}\right)$ & $\sigma\left(\mathrm{mN} \mathrm{m}^{-1}\right)$ \\
\hline Water & 18.0153 & $997.05^{a}$ & - & $71.97^{b}$ \\
$\left(\mathrm{NH}_{4}\right)_{2} \mathrm{SO}_{4}$ & 132.1388 & $1548.93^{c}$ & $1769.0^{d}$ & $99.66^{e}$ \\
Malonic acid & 104.062 & $1529.13^{f}$ & $1619.0^{d}(283.15 \mathrm{~K})$ & $48.24^{g}$ \\
\hline
\end{tabular}

${ }^{a}$ Pátek et al. (2009), ${ }^{b}$ IAPWS (2014), ${ }^{c}$ Extended from Tang and Munkelwitz (1994) ${ }^{d}$ CRC Handbook (1988) ${ }^{e}$ Fit into data from Hyvärinen et al. (2005) and Aumann et al. (2010) (details in the supplement), ${ }^{f}$ Topping et al. (2016) ${ }^{g}$ Hyvärinen et al. (2006)

\section{Results and discussion}

In the following sections, we present and discuss results of the Köhler model simulations with the different bulk-surface partitioning models. Köhler curves were calculated for dry particles of $D_{p}=50 \mathrm{~nm}$ consisting of one of the organic acids malonic acid, succinic acid or glutaric acid, mixed with ammonium sulphate in organic mass fractions $\left(w_{\mathrm{p}, \text { org }}\right)$ of 0.2 , 0.5 , 0.8 and 0.95 . Results are presented for the predicted equilibrium supersaturations $(S S)$, surface tensions $(\sigma)$ and organic partitioning factors $\left(n_{\mathrm{org}}^{S} / n_{\mathrm{org}}^{T}\right.$ ) of growing droplets at $298.15 \mathrm{~K}$. Results below focus on malonic acid-ammonium sulphate particles. Table 3 presents the droplet diameters, supersaturations and surface tensions at droplet activation predicted with the different partitioning models. The pure component properties used in the calculations are presented in Table 2. Corresponding results for simulations with succinic and glutaric acids as the organic component are presented in the supplement section S1, together with the required compound properties. 


\subsection{Köhler curves and droplet activation}

Figure 1 shows the Köhler curves, in terms of equilibrium supersaturation as a function of droplet diameter, predicted with each of the partitioning models for dry particles with $D_{p}=50 \mathrm{~nm}$ and organic mass fractions ( $w_{\mathrm{p}, \text { org }}$ ) of $0.2,0.5,0.8$ and 0.95. The critical point $\left(d_{c}, S S_{c}\right)$ is in each case determined as the maximum value of $S S$ along the Köhler curve, together with the corresponding droplet diameter. It is immediately clear from Fig. 1 that the different partitioning models lead to significantly different predictions of both $d_{c}$ and $S S_{c}$ for the same particle compositions. The divergence between results of the different models increases with mass fraction of surface active malonic acid in the particles, highlighting the strong dependency of results on the representation of malonic acid bulk-surface partitioning in the droplets. The Köhler curves predicted for particles containing succinic or glutaric acid (presented in supplement section S1) both have similar tendencies to the malonic acid predictions. The disparities between the results of the different models also increase with the mass fraction of the organic acid.

\subsubsection{Critical point}

For particles with $w_{\mathrm{p}, \text { org }}=0.2$ in Fig. 1(a), the Gibbs model predicts the lowest $S S_{c}$, followed by the partial organic film, bulk solution and monolayer models, while the compressed film model and the simple partitioning model predict the highest values of $S S_{c}$. The order is reversed for the critical diameters $\left(d_{c}\right)$, where the Gibbs model predicts the largest value, and the compressed film model the smallest (Table 3). Predicted $S S_{c}$ for all the partitioning models fall within a supersaturation range of $0.1 \%$, while the values for $d_{c}$ vary across a range of about $64 \mathrm{~nm}$. These ranges are simple absolute differences between the largest and smallest calculated values for $d_{c}$ and $S S_{c}$.

At $w_{\mathrm{p}, \text { org }}=0.5$ in Fig. 1(b), the relative order of $S S_{c}$ values predicted with the different partitioning models remains the same as in Fig. 1(a). The discrepancies between the Gibbs and partial organic film model predictions decreases. The compressed film model predicts a distinctly different shape of the Köhler curve, with the droplet growing considerably less under supersaturated conditions, compared to the predictions of the other models. The range of predicted $S S_{c}$ values increases compared to Fig. 1(a) and is now $0.19 \%$ supersaturation, while the predicted $d_{c}$ values are all within a range of $84 \mathrm{~nm}$. Lin et al. (2018) reported the monolayer model to predict lower $S S_{c}$ values than the Gibbs model for mixed succinic acid- $\mathrm{NaCl}$ particles with the same dry particle size and organic mass fraction. In this study, the situation is reversed, also for succinic acid (results presented in the supplement section S1). This is most likely an effect of mixing with ammonium sulphate instead of $\mathrm{NaCl}$, which could affect both surface activity of the organic (Prisle et al., 2012a) in the Gibbs framework, as well as the density of the surface phase in the monolayer framework.

At higher organic fractions, $w_{\mathrm{p}, \text { org }}=0.8$ in Fig. 1(c), the differences between the predictions with models where all organic is assumed to be partitioned to the surface along the entire growth curve (simple model and partial organic film model) and the models which account for evolving bulk-surface partitioning (monolayer model, Gibbs model and compressed film model) becomes much more apparent. The simple partitioning model predicts a significantly higher $S S_{c}$ than the other models, likely reflecting the strong absence of predicted solute effect in the droplets as the organic fraction increases. The partial organic film 
model predicts a considerably lower $S S_{c}$, and also occurring at a considerably smaller $d_{c}$, than the other models. The Köhler curve predicted with the partial organic film model also includes a local minimum, matching the point where the droplet surface film breaks and no longer fully encloses the bulk phase. The Köhler curves predicted with the bulk solution, Gibbs, and monolayer models group together with only small differences. The curve calculated with the compressed film model has a distinct shape, and the predicted $S S_{c}$ value falls between the monolayer and simple model predictions, but at the largest $d_{c}$. The range of predicted $S S_{c}$ increases to $0.5 \%$ supersaturation and the predicted $d_{c}$ range also increases to $199 \mathrm{~nm}$.

At $w_{\mathrm{p}, \text { org }}=0.95$ in Fig. 1(d), the results for supersaturation show similar trends as in Fig. 1(c). The most notable difference to Fig. 1(c) is that the partial organic film model predicts comparatively higher $S S_{c}$ in Fig.1(d) than it did in Fig. 1(c). The compressed film model again predicts the largest $d_{c}$ at a slightly lower $S S_{c}$ value than the bulk solution, Gibbs and monolayer models. In addition, a significant second local maximum is visible for the curve calculated with the compressed film model. This maximum is also present for the other surface active acids (results presented in the supplement) and we therefore made a sensitivity analysis of the model at this mass fraction (presented in the supplement section S2.4). The sensitivity analysis shows that the compressed film model predictions are quite robust with malonic and glutaric acid simulations in that the prediction of the critical point is stable with respect to relatively large variation in the model parameters. Simulations for succinic acid are more sensitive than for the other compounds. The increasing trend in the ranges of predicted $S S_{c}$ and $d_{c}$ with organic mass fraction in the dry particle continues to span ranges of $1.31 \%$ supersaturation and $282 \mathrm{~nm}$, respectively. In Fig. 1(d) we have included the experimental value for the $S S_{c}$ of malonic acid particles with at $D_{p}=48 \mathrm{~nm}$ from Rissman et al. (2007), who evaluated it from the results of Kumar et al. (2003). The monolayer, Gibbs, bulk and compressed film models all predict comparable $S S_{c}$ to the experimental value, while the partial organic film and the simple partitioning model predict considerably larger $S S_{c}$ values. Even though the experimental data is obtained at slightly different conditions than the present simulations, it is reasonable to assume that the latter model predictions will bias $S S_{c}$ values too high, as underlying assumptions may no longer be representative for the highest organic fractions in the particles. The high $S S_{c}$ values are an effect of the assumed complete partitioning of the organic to the surface and is in line with observations by Prisle et al. (2011) for how the simple model predictions differ from both experiments and detailed model predictions (Prisle et al., 2010) at high organic mass fractions, even with fatty acid salts and SDS, all relatively strong surfactants.

\subsubsection{Shape of droplet growth curves}

Predictions with the compressed film model are distinct from the other partitioning models (see Table 3), in that $S S_{c}$ values

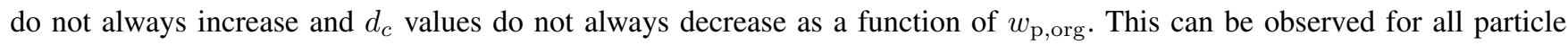
systems in this work (see supplement for results for succinic and glutaric acid particles). The Köhler curves predicted with the compressed film model and the simple partitioning model merge for higher organic mass fractions, after the droplets grow beyond the activation point of the compressed film model Köhler curve (as evident in Figs. 1(c) and 1(d) and also suggested in Fig. 1(b)). This is likely due to closely similar conditions in simulations with the two models, since in the compressed film model calculations, all organic has partitioned to the surface and the surface tension is equal to that of pure water after the point 
of droplet activation. For the calculations with the simple partitioning model, both these assumptions are made for the whole droplet growth curve.

In the partial organic film model, complete surface partitioning of the organic component is assumed along the whole Köhler curve, but the surface tension is calculated via Eq. (9). The partial organic film model predictions agree well with the monolayer, Gibbs and bulk solution models for particles with lower organic mass fractions, with the Köhler curve falling between those predicted with the Gibbs and the other two models in Figs. 1(a) and 1(b). In Fig. 1(c), the $S S_{c}$ values are still similar, but the partial organic film model predicts activation at a noticeably smaller droplet size than the other models. For malonic acid particles with $w_{\mathrm{p}, \text { org }}$ of 0.8 and 0.95 (Figs. 1(c) and 1(d)), Köhler curves predicted with the partial organic film model nearly converge with those predicted with the monolayer, Gibbs and bulk solution models after the monolayer breaks, however, for succinic and glutaric acid particles (see supplement), Köhler curves predicted with the partial organic film model show larger differences from the other models.

Prisle et al. (2019) modeled the CCN activity of six pollenkitts in pure pollenkitt particles or mixed with $20 \%$ by mass of ammonium sulphate, using the bulk solution, Gibbs and simple partitioning models. They found that the bulk solution model generally predicted significantly lower $S S_{c}$ values compared to the Gibbs and simple partitioning models but that none of the three models were able to capture the measured pollenkitt CCN activity well over the full range of particle sizes studied. In Fig. 1 the situation is different, as we find the Gibbs model predicting slightly lower $S S_{c}$ values than the bulk solution model for $w_{\mathrm{p}, \text { org }}=0.2,0.5$ and 0.8 (Table 3 ). These differences likely reflect the surface activity of the organic component. While pollenkitt is a complex mixture of acidic and other organic compounds, the substance has significant ability to reduce aqueous solution surface tension. According to Prisle et al. (2019) both pollenkitts used in the study are able to reduce aqueous surface tension to values below $50 \mathrm{mN} \mathrm{m}^{-1}$ at concentrations of about $0.1 \mathrm{~g} \mathrm{~L}^{-1}$. Estimating the surface tension in an aqueous solution of malonic acid at same concentration according to the fit of Hyvärinen et al. (2006), we do not see any surface tension depression. The pure surface tension of malonic acid is estimated according to Hyvärinen et al. (2006) to be about 48.24 $\mathrm{mN} \mathrm{m}^{-1}$ at $298.15 \mathrm{~K}$, which is lower than any surface tension depression reported by Hyvärinen et al. (2006).

Lin et al. (2018) found that for succinic acid-NaCl particles, across $D_{p}=50-150 \mathrm{~nm}$ for mass fraction range of $w_{\mathrm{p}, \text { org }}=$ $0-1$, the monolayer model predicts slightly lower critical supersaturation compared to the Gibbs model. In Table 3, the predicted $S S_{c}$ of the monolayer model is slightly larger than that of the Gibbs model for $w_{\mathrm{p}, \text { org }}=0.2,0.5,0.8$ of malonic acid. For succinic acid-ammonium sulphate particles in Table $\mathrm{S} 2$ of the supplement, the monolayer model predicts slightly higher $S S_{c}$ across all calculated compositions. As mentioned in relation to Fig. 1(b), this is likely due to the different salt present in the particles.

385 Davies et al. (2019) calculated Köhler curves for $100 \mathrm{~nm}$ particles over a range of compositions for particles comprising suberic acid and ammonium sulphate. In their calculations, the partial film model consistently predicted lower $S S_{c}$ than the compressed film model for organic volume fractions up to about 0.8 . This was also found for each of the organic acids in this study, except at the highest mass fraction $w_{\mathrm{p}, \text { org }}=0.95$, which would correspond to a suberic acid volume fraction of 0.965 the ammonium sulphate particles of Davies et al. (2019). 
(a) $w_{p, o r g}=0.2$

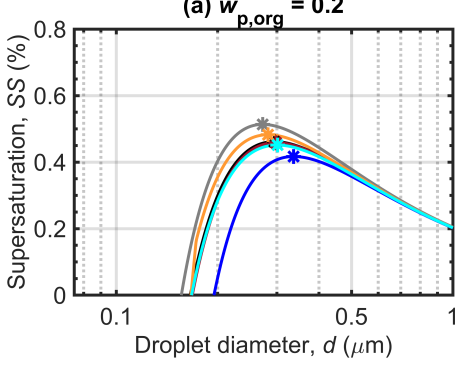

(c) $w_{\mathrm{p}, \mathrm{org}}=0.8$

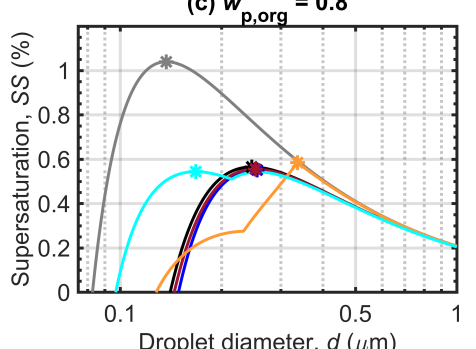

(b) $w_{p, o r g}=0.5$

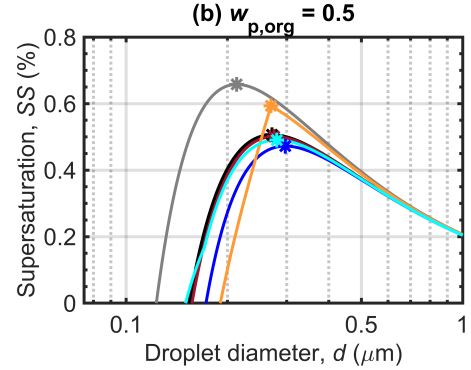

(d) $w_{\mathrm{p}, \mathrm{org}}=0.95$

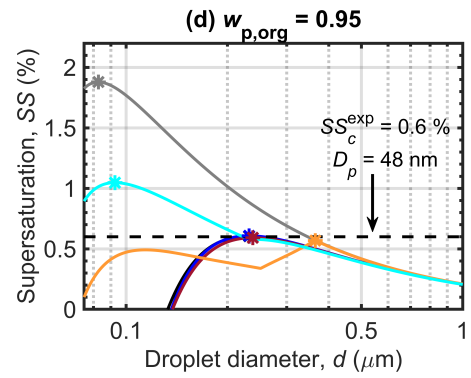

- Monolayer — Gibbs — Simple — Bulk solution — Compressed film — Partial film

Figure 1. Köhler curves calculated with the different partitioning models for dry malonic acid-ammonium sulphate particles with $D_{p}=50$ $\mathrm{nm}$. Each panel shows curves for particles with a different malonic acid mass fraction $\left(w_{\mathrm{p} \text {,org }}\right)$. The critical points are marked on each curve and the experimental critical supersaturation reported by Rissman et al. (2007) for pure malonic acid particles (corresponding to $w_{\mathrm{p}, \text { org }}=1$ ) with $D_{p}=48 \mathrm{~nm}$ is included in panel (d). Note that the vertical axis scaling changes between the panels.

\subsection{Surface tension}

Figure 2 shows the droplet surface tensions calculated with the different partitioning models along the Köhler curves in Fig. 1 , for dry particles of $D_{p}=50 \mathrm{~nm}$ and with malonic acid mass fractions ( $w_{\mathrm{p}, \mathrm{org}}$ ) of $0.2,0.5,0.8$ and 0.95 (shown in separate panels). The position of the critical point of droplet activation is indicated for each surface tension curve as $\left(d_{c}, \sigma_{c}\right)$, where $\sigma_{c}$ is the droplet surface tension evaluated at $d_{c}$. For each of the models, predicted surface tension can be significantly reduced at the smaller droplet sizes in the beginning of the growth curve where droplets are most concentrated. However, in most cases, the surface tension at the point of activation is close to the pure water value. The simple partitioning model yields a constant surface tension equal to that of pure water, as part of the basic assumptions for the model. The surface tension of pure malonic acid is shown for reference, as a measure of the lowest physically realistic value for the droplet surface tension. The pure malonic acid surface tension is estimated according to the fit of Hyvärinen et al. (2006) (Table 2). The surface tension curves predicted for particles containing succinic and glutaric acids (presented in the supplement section S1) show similar relative behavior to the curves predicted for malonic acid. 
Figure 2(a) shows that for droplets formed on malonic acid particles with $w_{\mathrm{p}, \mathrm{org}}=0.2$, the surface tensions predicted along the Köhler curves with the monolayer, Gibbs and bulk solution models are similar, with the most visible differences at small droplet sizes. This indicates that the droplet compositions are similar with all three models, as surface tension has been evaluated from the same composition-dependent function (Eq. (S9) in the supplement). The smallest droplets are both most concentrated and have the largest surface area-to-bulk volume ratios, so any differences in the representation of bulk-surface partitioning are expected to be more visible here. The droplet surface tensions predicted at activation $\left(\sigma_{c}\right)$ are also very similar, as can be seen in Table 3. Quite to the contrary, the surface tension curve predicted with the compressed film model is very distinct. Droplet surface tension values start at a compound specific minimum surface tension value determined by the model parameter fitting (Ruehl et al., 2016), and then increase to the value for pure water towards the activation point. In Fig. 2(a), the first droplet size at which pure water surface tension is reached in the droplets does not correspond to the $d_{c}$ value (see Fig. 1, Table 3). This deviation from the typical behavior of the predictions as seen in Ruehl et al. (2016) could be an artefact due to the extrapolation of the model parameters outside of their validity region. In the compressed film model, the fitted model parameters are assumed to be constant across varying organic mass fractions and dry particle sizes (concentrations), but for real droplet solutions mixing properties are likely sufficiently non-ideal (i.e. excess mixing properties are non-zero) that the model parameters would be expected to show some variation across the mixing space. Forestieri et al. (2018) made a similar observation for oleic acid particles within their parameter fitting range, at $w_{\mathrm{p}, \text { org }}=0.8$ and $\mathrm{NaCl}$ seed particles of $80 \mathrm{~nm}$. For the partial organic film model, droplet surface tensions start at the value of the pure organic compound (corresponding to complete surface coverage by the organic). The surface tension begins to increase as the droplet grows once the organic film breaks and the surface is no longer completely covered. In Fig. 2(a), all the $\sigma_{c}$ vales are within $3.1 \mathrm{mN} \mathrm{m}^{-1}$ of the surface tension of water (Table 3 ) and the lowest $\sigma_{c}$ is predicted with the partial organic film model.

The results for predicted surface tensions shown in Figs. 2(b), 2(c) and 2(d) for particles with higher mass fractions of malonic acid have very similar trends between the different models as seen in Fig. 2(a). The monolayer, Gibbs and bulk solution models predict similar surface tensions and $\sigma_{c}$ decreases with increasing $w_{\mathrm{p}, \mathrm{org}}$. With the compressed film model, the difference from Fig. 2(a) are the droplet sizes where the surface tension starts increasing from the minimum value and where activation occurs. In Figs. 2(b), 2(c) and 2(d), the activation point and the water surface tension are reached at the same droplet size. With the partial organic film model, the calculated droplet size at which the organic film breaks increases while $\sigma_{c}$ decreases with increasing $w_{\mathrm{p} \text {,org }}$, to eventually reach the pure organic surface tension value for the highest malonic acid mass fractions studied in Fig. 2(d). Of all the models compared here, both the partitioning models and the bulk solution model, the partial organic film model predicts the lowest surface tension at droplet activation, as can be seen in Fig. 2 and Table 3. Ovadnevaite et al. (2017) also reported a reduced surface tension with simplified model calculations when compared to their full LLPS framework, indicating that the simplified model calculations provide a limit to the expected reduction in droplet surface tension during activation. Excluding predictions with the partial organic film model, the other predicted $\sigma_{c}$ values for malonic acid particle mixtures are within $1.3 \mathrm{mN} \mathrm{m}^{-1}$ of the surface tension of water. This moderate surface tension depression agrees well with the predictions of Prisle et al. (2019) for pollenkitt modeled using the Gibbs model. It should however be noted that Prisle et al. (2019) always predict considerably lower surface tensions (several tens of $\mathrm{mN} \mathrm{m}^{-1}$ ) at activation with the bulk 

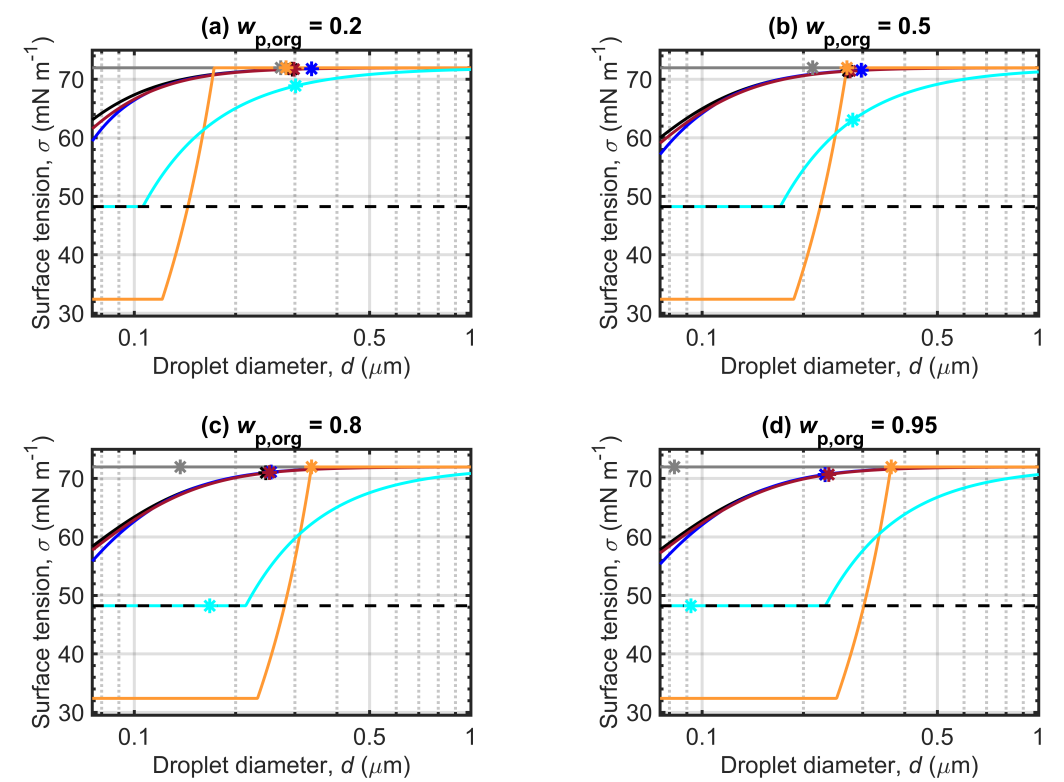

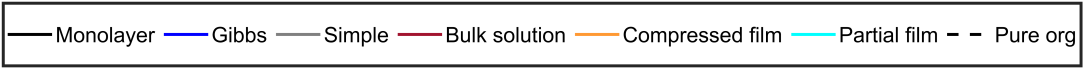

Figure 2. Surface tensions of droplets along the Köhler curves, calculated with the different partitioning models for dry particles of $D_{p}=50$ $\mathrm{nm}$ at different malonic acid mass fractions $\left(w_{\mathrm{p}, \mathrm{org}}\right)$. The critical points evaluated for the Köhler curves in Fig. 1 are also marked, and the surface tension of pure malonic acid estimated though the fit of Hyvärinen et al. (2006) is indicated as a physical lower limit for the droplet surface tension.

solution model than with the Gibbs model. This is also the case here for all but the largest organic mass fraction, but the differences between the model predictions are considerably smaller $\left(\sim 0.1 \mathrm{mN} \mathrm{m}^{-1}\right.$, Table 3$)$.

\subsection{Organic bulk-surface partitioning}

Figure 3 shows the surface partitioning factors of malonic acid calculated with the different models for $D_{p}=50 \mathrm{~nm}$ particles with organic mass fractions $\left(w_{\mathrm{p}, \mathrm{org}}\right)$ of $0.2,0.5,0.8$ and 0.95 . The partitioning factor $\left(n_{\mathrm{org}}^{S} / n_{\mathrm{org}}^{T}\right)$ is defined as the fraction of the total amount of organic molecules in the droplet which are predicted to reside in the surface. The simple partitioning model and the partial organic film model calculations are made with the assumption that all organic is always partitioned to the droplet surface and therefore the partitioning factor is equal to unity for all droplet states. The bulk solution model has no partitioning and therefore the partitioning factor is zero. Between the three models that calculate droplet state dependent partitioning (monolayer, Gibbs, and compressed film), large differences are seen in the predicted values of $n_{\mathrm{org}}^{S} / n_{\mathrm{org}}^{T}$ for malonic acid. At the point of activation, the compressed film model predicts nearly all malonic acid is partitioned to the droplet surface, whereas the Gibbs and monolayer models both predict a moderate fraction (well below 20\%) of all malonic acid solute in the surface. These significant differences between the frameworks correspond to very different solution states for the same 
Table 3. The critical droplet diameters $\left(d_{c}\right)$, supersaturations $\left(S S_{c}\right)$ and surface tensions $\left(\sigma_{c}\right)$ predicted with the different models in simulations for mixed malonic acid-ammonium sulfate particles of $D_{p}=50 \mathrm{~nm}$ at $298.15 \mathrm{~K}$.

\begin{tabular}{lccccccccc}
\hline Parameter & $d_{c}(\mathrm{~nm})$ & $S S_{c}(\%)$ & $\sigma_{c}\left(\mathrm{mN} \mathrm{m}^{-1}\right)$ & $d_{c}(\mathrm{~nm})$ & $S S_{c}(\%)$ & $\sigma_{c}\left(\mathrm{mN} \mathrm{m}^{-1}\right)$ & $d_{c}(\mathrm{~nm})$ & $S S_{c}(\%)$ & $\sigma_{c}\left(\mathrm{mN} \mathrm{m}^{-1}\right)$ \\
\hline$w_{\mathrm{p}, \text { org }}$ & \multicolumn{3}{c}{ Monolayer } & \multicolumn{3}{c}{ Gibbs } & \multicolumn{3}{c}{ Simple } \\
0.2 & 294.97 & 0.46 & 71.73 & 336.43 & 0.42 & 71.81 & 272.19 & 0.51 & 71.97 \\
0.5 & 271.19 & 0.51 & 71.43 & 297.13 & 0.47 & 71.56 & 213.09 & 0.66 & 71.97 \\
0.8 & 245.72 & 0.57 & 70.97 & 254.86 & 0.55 & 71.09 & 136.96 & 1.04 & 71.97 \\
0.95 & 231.77 & 0.6 & 70.65 & 231.77 & 0.61 & 70.68 & 82.72 & 1.88 & 71.97 \\
\hline \multirow{2}{*}{$w_{\mathrm{p}, \text { org }}$} & \multicolumn{3}{c}{ Bulk solution } & \multicolumn{3}{c}{ Compressed film } & \multicolumn{2}{c}{ Partial organic film } \\
0.2 & 298.22 & 0.46 & 71.73 & 282.31 & 0.48 & 71.97 & 301.5 & 0.45 & 68.87 \\
0.5 & 275.19 & 0.5 & 71.43 & 269.22 & 0.59 & 71.97 & 280.26 & 0.49 & 63.04 \\
0.8 & 252.08 & 0.56 & 71.0 & 336.43 & 0.58 & 71.97 & 167.43 & 0.54 & 48.24 \\
0.95 & 237.77 & 0.59 & 70.68 & 364.58 & 0.57 & 71.97 & 92.64 & 1.05 & 48.24 \\
\hline
\end{tabular}

overall droplet compositions. Similar predictions were also observed for particles containing succinic and glutaric acids. More details can be found in supplement section S1.

Figure 3(a) shows that for particles with malonic acid fractions of $w_{\mathrm{p}, \text { org }}=0.2$, the monolayer model predicts stronger surface partitioning of malonic acid than the Gibbs model, especially at smaller droplet sizes. As the droplet grows, the partitioning factors predicted by the Gibbs model approach those of the monolayer model. Compared to the other two partitioning models, $n_{\text {org }}^{S} / n_{\text {org }}^{T}$ predicted by the compressed film model is very pronounced, always above 0.9 . We also note a decrease in $n_{\mathrm{org}}^{S} / n_{\mathrm{org}}^{T}$ to a minimum value before increasing towards unity, as expected. The minimum value is due to the unconstrained partitioning factor and has no physical meaning for the Köhler curve (Fig. 1) until the surface tension (Fig. 2) starts increasing from its minimum value (Eq. (6)). This is because the surface tension is the quantity being constrained by the parameter $\sigma_{\min }$ in the framework.

For Figs. 3(b), 3(c) and 3(d), the surface partitioning factor predicted with Gibbs model is slightly higher than with the monolayer for all but the smallest droplets. The differences between the different malonic acid mass fractions is more noticeable for predictions with the monolayer model, as the amount of molecules in the surface is constrained by the volume of the molecular monolayer (Malila and Prisle, 2018) while the Gibbs model has no constraint on the extent of surface partitioning. The partitioning factors predicted with Gibbs model are very similar across the droplet size range of the Köhler curves for malonic acid mass fractions $w_{\mathrm{p}, \text { org }}=0.5,0.8$ and 0.95 and the same can be seen for the compressed film model. At droplet activation, the partitioning factors predicted here with the Gibbs and monolayer models are similar to the values reported by Lin et al. (2018) for mixed succinic acid and $\mathrm{NaCl}$ particles with the same dry size and $w_{\mathrm{p}, \mathrm{org}}=0.5$. With the compressed film model, the predicted partitioning factors are higher, but comparable to the results of Ruehl et al. (2016), where the values for malonic acid dry particles of $150 \mathrm{~nm}$ and $w_{\mathrm{p}, \text { org }}=0.96$ are always larger than approximately 0.65 . 

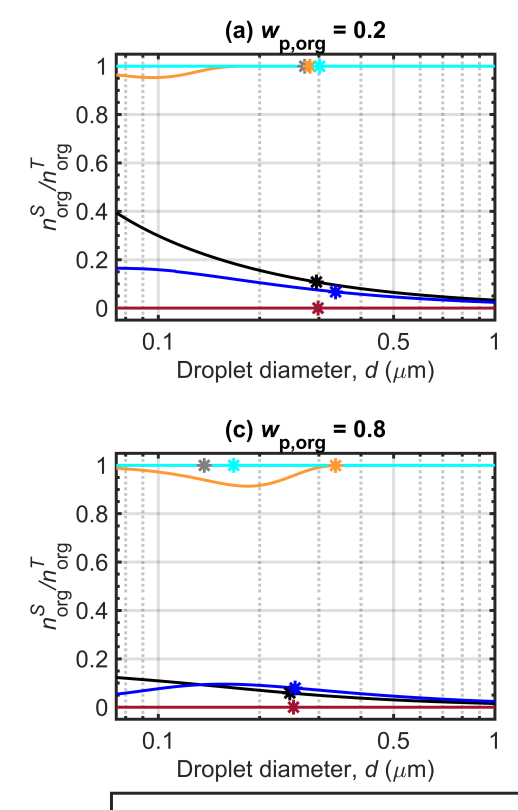

- Monolayer — Gibbs — Simple
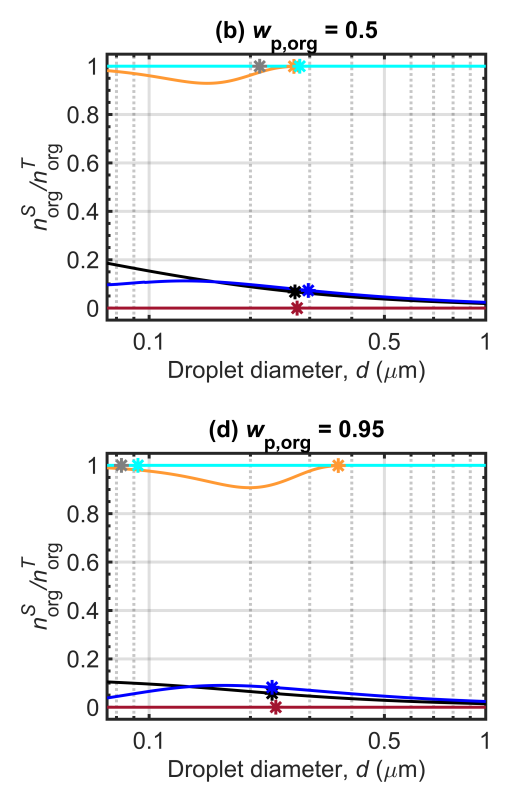

Droplet diameter, $d(\mu \mathrm{m})$

Bulk solution $\_$Compressed film $\_$Partial film

Figure 3. Malonic acid surface partitioning factors $\left(n_{\mathrm{org}}^{S} / n_{\mathrm{org}}^{B}\right)$ predicted with the different models along the Köhler curves for dry particles with $D_{p}=50 \mathrm{~nm}$ at different organic mass fractions $\left(w_{\mathrm{p}, \mathrm{org}}\right)$. The critical points are also marked.

\section{Conclusions}

We have compared Köhler model predictions for particles comprising moderately strong organic surfactants, using six different approaches to describe bulk-surface partitioning in the growing droplets. Specifically, we used the monolayer (Malila and Prisle, 2018), Gibbs (Prisle et al., 2010), simple (Prisle et al., 2011), compressed film (Ruehl et al., 2016), partial organic film (Ovadnevaite et al., 2017) and a bulk solution models to predict possible bulk-surface partitioning effects during Köhler calculations for particles of $D_{p}=50 \mathrm{~nm}$ consisting of atmospherically relevant dicarboxylic acids mixed with ammonium sulphate over a range of compositions. From the Köhler calculations, we evaluated the droplet mixing state in terms of bulk and surface compositions, droplet surface tension and resulting equilibrium water saturation ratio, as well as the critical point of droplet activation from the Köhler growth curve maximum and corresponding diameter.

When the mass fraction of surface active organic is small $(<50 \%)$, the predicted Köhler growth curves and critical supersaturation values for droplet activation are similar between the models. For particles with high mass fractions $(>80 \%)$ of organic, the full partitioning models (monolayer, Gibbs, and compressed film) all predict similar critical supersaturations as the bulk solution model for the investigated dicarboxylic acid systems, although the compressed film model predicts larger critical droplets. Despite these overall similarities, there are however large differences between the different models in the predicted degree of surface partitioning of the organic component. Between the full partitioning models, the degree of organic surface 
partitioning predicted with the compressed film model is significantly higher than with either the Gibbs or surface monolayer models.

For all surface active organic mass fractions in the particles, the different models predict very different surface tension curves for the growing droplets. The surface monolayer and Gibbs partitioning models use the same surface tension parametrizations as the bulk solution model and all predict surface tension curves of similar shape, reflecting similar mixing states of the growing droplets. For the simple partitioning model, droplets are predicted to have a constant surface tension, while the compressed and partial organic film models each predict distinct surface tension curves, reflecting the underlying assumptions regarding both the bulk-surface partitioning and surface tension equation of state. The predicted droplet surface tensions at the point of activation are comparable for all models at small organic fractions in the particles, but differences between the models increase with the organic fraction. The partial organic film model consistently predicts the lowest surface tension at droplet activation, for some particle compositions as low as the surface tension for the pure organic. The other models predict only moderate or no surface tension depression in droplets at activation.

Among the models used in this work, the Gibbs, monolayer, and compressed film models evaluate the progression of the bulk-surface partitioning equilibrium with mixing state as the droplets grow, whereas the simple partitioning and partial organic film models rely on the simplifying assumption that the organic is completely partitioned to the droplet surface. We see that for particles where the fraction of organic is not too large, the latter models can still yield similar results as the comprehensive models, but underlying assumptions may become increasingly misrepresentative as the fraction of surface active organic in the particles becomes larger. Regarding the comprehensive partitioning models, the Gibbs and monolayer models predict similar droplet properties at activation as the bulk solution model, due to the modest degree of organic surface partitioning at activation, which seems realistic for dilute solutions of a moderate surfactant, and because models use the same surface tension parametrizations based on independent measurements. The compressed film model on the other hand uses a surface tension equation of state with parameters which are obtained by fitting to experimental droplet growth curves similar to those predicted and predicts very strong surface partitioning and surface tension depression in the growing droplets. Overall, this comparison of partitioning model predictions strongly highlights the need for experimental validation of the predictions from different droplet partitioning models across a wide range of particle mixtures, before either model is used as basis for broad generalizations of results to atmospheric processes. A recent development has been the reformulation of Köhler theory via a Gibbs model to directly include water-soluble species and surfactants (McGraw and Wang, 2021). In future work, a similar comparison between different models will be done with more strongly surface active particle components.

Code and data availability.

Author contributions. SV adopted the models for the study, did the model simulations, and performed the analysis of model results with 
https://doi.org/10.5194/acp-2021-561

Preprint. Discussion started: 26 July 2021

(c) Author(s) 2021. CC BY 4.0 License.

(c) (i)

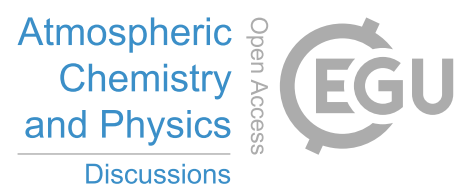

and JM. NLP conceived the project and methodology, was responsible for the supervision and project management and secured the funding for the work.

Competing interests. There are no conflicts to declare.

Acknowledgements. We thank Chris Ruehl and Chris Cappa for providing and discussing their codes of the compressed film model. We also 520 thank Andreas Zuend for providing the surface coverage and surface tension calculation routine used for the partial organic film model. This project has received funding from the European Research Council (ERC) under the European Union's Horizon 2020 research and innovation programme, Project SURFACE (Grant Agreement No. 717022). The authors also gratefully acknowledge the financial contribution from the Academy of Finland (Grant Nos. 308238, 314175, and 335649). 


\section{References}

AIOMFAC-web: version 2.32, https://aiomfac.lab.mcgill.ca, accessed: 2020-08-19.

Aumann, E., Hildemann, L. M., and Tabazadeh, A.: Measuring and modeling the composition and temperature-dependence of surface tension for organic solutions, Atmos. Environ., 44, 329-337, https://doi.org/10.1016/j.atmosenv.2009.10.033, 2010.

Bondi, A.: Van der Waals Volumes and Radii, J. Phys. Chem., 68, 441-451, https://doi.org/10.1021/j100785a001, 1964.

Booth, A. M., Topping, D. O., McFiggans, G., and Percival, C. J.: Surface tension of mixed inorganic and dicarboxylic acid aqueous solutions at $298.15 \mathrm{~K}$ and their importance for cloud activation predictions, Phys. Chem. Chem. Phys., 11, 8021-8028, https://doi.org/10.1039/B906849J, 2009.

Bzdek, B. R., Reid, J. P., Malila, J., and Prisle, N. L.: The surface tension of surfactant-containing, finite volume droplets, Proc. Natl. Acad. Sci. U.S.A., 117, 8335-8343, https://doi.org/10.1073/pnas.1915660117, 2020.

Cheng, Y., Li, S.-M., Leithead, A., Brickell, P. C., and Leaitch, W. R.: Characterizations of cis-pinonic acid and n-fatty acids on fine aerosols in the Lower Fraser Valley during Pacific 2001 Air Quality Study, Atmos. Environ., 38 , 5789 - 5800, https://doi.org/https://doi.org/10.1016/j.atmosenv.2004.01.051, 2004.

CRC Handbook: CRC Handbook of Chemistry and Physics, 1st Student Edition, CRC Press, Boca Raton, FL., 1988.

Davies, J. F., Zuend, A., and Wilson, K. R.: Technical note: The role of evolving surface tension in the formation of cloud droplets, Atmos. Chem. Phys., 19, 2933-2946, https://doi.org/10.5194/acp-19-2933-2019, 2019.

540 Defay, R. and Prigogine, I.: Surface tension and adsorption, Longmans, Green \& Co, Bristol, 1966.

Facchini, M. C., Mircea, M., Fuzzi, S., and Charlson, R. J.: Cloud albedo enhancement by surface-active organic solutes in growing droplets, Nature, 401, 257-259, https://doi.org/10.1038/45758, 1999.

Facchini, M. C., Decesari, S., Mircea, M., Fuzzi, S., and Loglio, G.: Surface tension of atmospheric wet aerosol and cloud/fog droplets in relation to their organic carbon content and chemical composition, Atmos. Environ., 34, 4853-4857, https://doi.org/10.1016/S13522310(00)00237-5, 2000.

Forestieri, S. D., Staudt, S. M., Kuborn, T. M., Faber, K., Ruehl, C. R., Bertram, T. H., and Cappa, C. D.: Establishing the impact of model surfactants on cloud condensation nuclei activity of sea spray aerosol mimics, Atmos. Chem. Phys., 18, 10985-11005, https://doi.org/10.5194/acp-18-10985-2018, 2018.

Gérard, V., Nozière, B., Baduel, C., Fine, L., Frossard, A. A., and Cohen, R. C.: Anionic, Cationic, and Nonionic Surfactants in Atmospheric Aerosols from the Baltic Coast at Askö, Sweden: Implications for Cloud Droplet Activation, Environ. Sci. Technol., 50, 2974-2982, https://doi.org/10.1021/acs.est.5b05809, 2016.

Gérard, V., Noziere, B., Fine, L., Ferronato, C., Singh, D. K., Frossard, A., Cohen, R. C., Asmi, E., Lihavainen, H., Kivekäs, N., Aurela, M.,

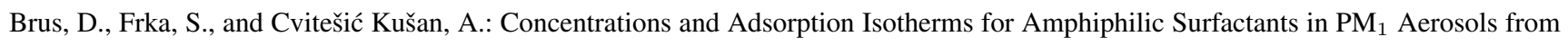
Different Regions of Europe, Environ. Sci. Technol., 53, 12 379-12 388, https://doi.org/10.1021/acs.est.9b03386, 2019.

Gibbs, J. W.: On the equilibrium of heterogeneous substances (concluded), Trans. Connecticut Acad. Arts Sci., 3, 343-524, 1878.

Gieré, R. and Querol, X.: Solid Particulate Matter in the Atmosphere, Elements, 6, 215-222, https://doi.org/10.2113/gselements.6.4.215, 2010.

Giordano, M. R., Short, D. Z., Hosseini, S., Lichtenberg, W., and Asa-Awuku, A. A.: Changes in Droplet Surface Tension Affect the Observed Hygroscopicity of Photochemically Aged Biomass Burning Aerosol, Environ. Sci. Technol, 47, 10980-10986, https://doi.org/10.1021/es401867j, 2013. 
Hansen, A. M. K., Hong, J., Raatikainen, T., Kristensen, K., Ylisirniö, A., Virtanen, A., Petäjä, T., Glasius, M., and Prisle, N. L.: Hygroscopic properties and cloud condensation nuclei activation of limonene-derived organosulfates and their mixtures with ammonium sulfate, Atmos. Chem. Phys., 15, 14 071-14 089, https://doi.org/10.5194/acp-15-14071-2015, 2015.

Hori, M., Ohta, S., Murao, N., and Yamagata, S.: Activation capability of water soluble organic substances as CCN, J. Aerosol Sci., 34,419 - 448, https://doi.org/https://doi.org/10.1016/S0021-8502(02)00190-8, 2003.

Hyvärinen, A.-P., Raatikainen, T., Laaksonen, A., Viisanen, Y., and Lihavainen, H.: Surface tensions and densities of $\mathrm{H}_{2} \mathrm{SO}_{4}+\mathrm{NH}_{3}+$ water solutions, Geophys. Res. Lett., 32, 1-5, https://doi.org/10.1029/2005GL023268, 2005.

Hyvärinen, A.-P., Lihavainen, H., Gaman, A., Vairila, L., Ojala, H., Kulmala, M., and Viisanen, Y.: Surface Tensions and Densities of Oxalic, Malonic, Succinic, Maleic, Malic, and cis-Pinonic Acids, J. Chem. Eng. Data, 51, 255-260, https://doi.org/10.1021/je050366x, 2006.

Hänel, G.: The Properties of Atmospheric Aerosol Particles as Functions of the Relative Humidity at Thermodynamic Equilibrium with the Surrounding Moist Air, Adv. Geophys., 19, 73 - 188, https://doi.org/https://doi.org/10.1016/S0065-2687(08)60142-9, 1976.

IAPWS: Revised Release on Surface Tension of Ordinary Water Substance, IAPWS, http://www.iapws.org/relguide/Surf-H2O.html, 2014.

IPCC: Climate Change 2013: The Physical Science Basis. Contribution of Working Group I to the Fifth Assessment Report of the Intergovernmental Panel on Climate Change, Cambridge University Press, Cambridge, United Kingdom and New York, NY, USA, https://doi.org/10.1017/CBO9781107415324, 2013.

Jung, J., Tsatsral, B., Kim, Y. J., and Kawamura, K.: Organic and inorganic aerosol compositions in Ulaanbaatar, Mongolia, during the cold winter of 2007 to 2008: Dicarboxylic acids, ketocarboxylic acids, and $\alpha$-dicarbonyls, J. Geophys. Res.: Atmos, 115, https://doi.org/https://doi.org/10.1029/2010JD014339, 2010.

Jura, G. and Harkins, W. D.: Surfaces of solids. XIV. A unitary thermodynamic theory of the adsorption of vapors on solids and of insoluble films on liquid subphases, J. Am. Chem. Soc., 68, 1941-1952, 1946.

Khwaja, H. A.: Atmospheric concentrations of carboxylic acids and related compounds at a semiurban site, Atmos. Environ., 29, 127 - 139, https://doi.org/https://doi.org/10.1016/1352-2310(94)00211-3, 1995.

Kroflič, A., Frka, S., Simmel, M., Wex, H., and Grgić, I.: Size-Resolved Surface-Active Substances of Atmospheric Aerosol: Reconsideration of the Impact on Cloud Droplet Formation, Environ. Sci. Technol., 52, 9179-9187, https://doi.org/10.1021/acs.est.8b02381, 2018.

Kumar, P. P., Broekhuizen, K., and Abbatt, J. P. D.: Organic acids as cloud condensation nuclei: Laboratory studies of highly soluble and insoluble species, Atmos. Chem. Phys., 3, 509-520, https://doi.org/10.5194/acp-3-509-2003, 2003.

Köhler, H.: The nucleus in and the growth of hygroscopic droplets, Trans. Faraday Soc., 32, 1152-1161, https://doi.org/10.1039/TF9363201152, 1936.

Laaksonen, A. and Kulmala, M.: An explicit cluster model for binary nuclei in water-alcohol systems, J. Chem. Phys., 95, 6745-6748, https://doi.org/10.1063/1.461513, 1991.

Li, W. and Shao, L.: Transmission electron microscopy study of aerosol particles from the brown hazes in northern China, J. Geophys. Res. D: Atmos., 114, https://doi.org/10.1029/2008JD011285, 2009.

Li, Y.-c. and Yu, J. Z.: Simultaneous Determination of Mono- and Dicarboxylic Acids, $\omega$-Oxo-carboxylic Acids, Midchain Ketocarboxylic Acids, and Aldehydes in Atmospheric Aerosol Samples, Environmental Science \& Technology, 39, 7616-7624, https://doi.org/10.1021/es050896d, pMID: 16245835, 2005.

Li, Z., Williams, A. L., and Rood, M. J.: Influence of Soluble Surfactant Properties on the Activation of Aerosol Particles Containing Inorganic Solute, J. Atmos. Sci., 55, 1859-1866, https://doi.org/10.1175/1520-0469(1998)055<1859:IOSSPO>2.0.CO;2, 1998. 
Lin, J. J., Malila, J., and Prisle, N. L.: Cloud droplet activation of organic-salt mixtures predicted from two model treatments of the droplet surface, Environ. Sci.: Processes Impacts, 20, 1611-1629, https://doi.org/10.1039/c8em00345a, 2018.

Lin, J. J., Kristensen, T. B., Calderón, S. M., Malila, J., and Prisle, N. L.: Effects of surface tension time-evolution for CCN activation of a complex organic surfactant, Environ. Sci.: Processes Impacts, 22, 271-284, https://doi.org/10.1039/C9EM00426B, 2020.

Lowe, S. J., Partridge, D. G., Davies, J. F., Wilson, K. R., Topping, D., and Riipinen, I.: Key drivers of cloud response to surface-active organics, Nat. Commun., 10, 5214, https://doi.org/10.1038/s41467-019-12982-0, 2019.

Malila, J. and Prisle, N. L.: A Monolayer Partitioning Scheme for Droplets of Surfactant Solutions, J. Adv. Model. Earth Syst., 10, 32333251, https://doi.org/10.1029/2018MS001456, 2018.

MATLAB: version 9.6.0.1072779 (R2019a), The MathWorks Inc., Natick, Massachusetts, 2019.

MATLAB: version 9.8.0.1323502 (R2020a), The MathWorks Inc., Natick, Massachusetts, 2020.

McGraw, R. and Wang, J.: Surfactants and cloud droplet activation: A systematic extension of Köhler theory based on analysis of droplet stability, J. Chem. Phys., 154, 024 707, https://doi.org/10.1063/5.0031436, 2021.

610 Mochida, M., Kitamori, Y., Kawamura, K., Nojiri, Y., and Suzuki, K.: Fatty acids in the marine atmosphere: Factors governing their concentrations and evaluation of organic films on sea-salt particles, J. Geophys. Res.: Atmos, 107 (D17), 4325, https://doi.org/https://doi.org/10.1029/2001JD001278, 2002.

Mochida, M., Umemoto, N., Kawamura, K., Lim, H.-J., and Turpin, B. J.: Bimodal size distributions of various organic acids and fatty acids in the marine atmosphere: Influence of anthropogenic aerosols, Asian dusts, and sea spray off the coast of East Asia, J. Geophys. Res.: Atmos, 112, https://doi.org/https://doi.org/10.1029/2006JD007773, 2007.

Nozière, B., Baduel, C., and Jaffrezo, J.-L.: The dynamic surface tension of atmospheric aerosol surfactants reveals new aspects of cloud activation, Nat. Commun., 5, 3335, https://doi.org/10.1038/ncomms4335, 2014.

Nozière, B., Gérard, V., Baduel, C., and Ferronato, C.: Extraction and Characterization of Surfactants from Atmospheric Aerosols., J. Visualized Exp., 122, e55 622, https://doi.org/10.3791/55622, 2017.

Ovadnevaite, J., Zuend, A., Laaksonen, A., Sanchez, K. J., Roberts, G., Ceburnis, D., Decesari, S., Rinaldi, M., Hodas, N., Facchini, M. C., Seinfeld, J. H., and O'Dowd, C.: Surface tension prevails over solute effect in organic-influenced cloud droplet activation, Nature, 546, 637-641, https://doi.org/10.1038/nature22806, 2017.

Padró, L. T., Tkacik, D., Lathem, T., Hennigan, C. J., Sullivan, A. P., Weber, R. J., Huey, L. G., and Nenes, A.: Investigation of cloud condensation nuclei properties and droplet growth kinetics of the water-soluble aerosol fraction in Mexico City, J. Geophys. Res. D: Atmos., 115, D09 204, https://doi.org/10.1029/2009JD013195, 2010.

Petters, M. D. and Kreidenweis, S. M.: A single parameter representation of hygroscopic growth and cloud condensation nucleus activity Part 3: Including surfactant partitioning, Atmos. Chem. Phys., 13, 1081-1091, https://doi.org/10.5194/acp-13-1081-2013, 2013.

Petters, S. S. and Petters, M. D.: Surfactant effect on cloud condensation nuclei for two-component internally mixed aerosols, J. Geophys. Res. D: Atmos., 121, 1878-1895, https://doi.org/10.1002/2015JD024090, 2016.

630 Prisle, N., Ottosson, N., Ohrwall, G., Söderström, J., Dal Maso, M., and Björneholm, O.: Surface/bulk partitioning and acid/base speciation of aqueous decanoate: Direct observations and atmospheric implications, Atmos. Chem. Phys., 12, 12227-12242, https://doi.org/10.5194/acp-12-12227-2012, 2012a.

Prisle, N. L.: Cloud Condensation Nuclei Properties of Organic Aerosol Particles: Effects of Acid Dissociation and Surfactant Partitioning, Master's thesis, University of Copenhagen, Copenhagen, 2006. 
Prisle, N. L. and Mølgaard, B.: Modeling CCN activity of chemically unresolved model HULIS, including surface tension, non-ideality, and surface partitioning, Atmos. Chem. Phys. Discuss., 2018, 1-23, https://doi.org/10.5194/acp-2018-789, 2018.

Prisle, N. L., Raatikainen, T., Sorjamaa, R., Svenningsson, B., Laaksonen, A., and Bilde, M.: Surfactant partitioning in cloud droplet activation: a study of C8, C10, C12 and C14 normal fatty acid sodium salts, Tellus B, 60, 416-431, https://doi.org/10.1111/j.16000889.2008.00352.x, 2008.

Prisle, N. L., Raatikainen, T., Laaksonen, A., and Bilde, M.: Surfactants in cloud droplet activation: mixed organic-inorganic particles, Atmos. Chem. Phys., 10, 5663-5683, https://doi.org/10.5194/acp-10-5663-2010, 2010.

Prisle, N. L., Dal Maso, M., and Kokkola, H.: A simple representation of surface active organic aerosol in cloud droplet formation, Atmos. Chem. Phys., 11, 4073-4083, https://doi.org/10.5194/acp-11-4073-2011, 2011.

Prisle, N. L., Asmi, A., Topping, D., Partanen, A., Romakkaniemi, S., Dal Maso, M., Kulmala, M., Laaksonen, A., Lehtinen, K. E. J., McFiggans, G., and Kokkola, H.: Surfactant effects in global simulations of cloud droplet activation, Geophys. Res. Lett., 39, L05 802, https://doi.org/10.1029/2011GL050467, 2012b.

Prisle, N. L., Lin, J. J., Purdue, S., Lin, H., Meredith, J. C., and Nenes, A.: Cloud condensation nuclei activity of six pollenkitts and the influence of their surface activity, Atmos. Chem. Phys., 19, 4741-4761, https://doi.org/10.5194/acp-19-4741-2019, 2019.

Pátek, J., Hrubý, J., Klomfar, J., Součková, M., and Harvey, A. H.: Reference Correlations for Thermophysical Properties of Liquid Water at 0.1 MPa, J. Phys. Chem. Ref. Data, 38, 21-29, https://doi.org/10.1063/1.3043575, 2009.

Raatikainen, T. and Laaksonen, A.: A simplified treatment of surfactant effects on cloud drop activation, Geosci. Model Dev., 4, 107-116, https://doi.org/10.5194/gmd-4-107-2011, 2011.

Rissman, T. A., Varutbangkul, V., Surratt, J. D., Topping, D. O., McFiggans, G., Flagan, R. C., and Seinfeld, J. H.: Cloud condensation nucleus $(\mathrm{CCN})$ behavior of organic aerosol particles generated by atomization of water and methanol solutions, Atmos. Chem. Phys., 7 , 2949-2971, https://doi.org/10.5194/acp-7-2949-2007, 2007.

Ruehl, C. R. and Wilson, K. R.: Surface organic monolayers control the hygroscopic growth of submicrometer particles at high relative humidity, J. Phys. Chem. A, 118, 3952-3966, https://doi.org/10.1021/jp502844g, 2014.

Ruehl, C. R., Davies, J. F., and Wilson, K. R.: An interfacial mechanism for cloud droplet formation on organic aerosols, Science, 351, 1447-1450, https://doi.org/10.1126/science.aad4889, 2016.

Seinfeld, J. H., Bretherton, C., Carslaw, K. S., Coe, H., DeMott, P. J., Dunlea, E. J., Feingold, G., Ghan, S., Guenther, A. B., Kahn, R., Kraucunas, I., Kreidenweis, S. M., Molina, M. J., Nenes, A., Penner, J. E., Prather, K. A., Ramanathan, V., Ramaswamy, V., Rasch, P. J., Ravishankara, A. R., Rosenfeld, D., Stephens, G., and Wood, R.: Improving our fundamental understanding of the role of aerosol-cloud interactions in the climate system, Proc. Natl. Acad. Sci. U.S.A, 113, 5781-5790, https://doi.org/10.1073/pnas.1514043113, 2016.

Shulman, M. L., Jacobson, M. C., Carlson, R. J., Synovec, R. E., and Young, T. E.: Dissolution behavior and surface tension effects of organic compounds in nucleating cloud droplets, Geophys. Res. Lett., 23, 277-280, https://doi.org/10.1029/95GL03810, 1996.

Sorjamaa, R., Svenningsson, B., Raatikainen, T., Henning, S., Bilde, M., and Laaksonen, A.: The role of surfactants in Köhler theory reconsidered, Atmos. Chem. Phys., 4, 2107-2117, https://doi.org/10.5194/acp-4-2107-2004, 2004.

Tang, I. N. and Munkelwitz, H. R.: Water activities, densities, and refractive indices of aqueous sulfates and sodium nitrate droplets of atmospheric importance, J. Geophys. Res. D: Atmos., 99, 18 801-18 808, https://doi.org/10.1029/94JD01345, 1994.

670 Topping, D.: An analytical solution to calculate bulk mole fractions for any number of components in aerosol droplets after considering partitioning to a surface layer, Geosci. Model Dev., 3, 635-642, https://doi.org/10.5194/gmd-3-635-2010, 2010. 
https://doi.org/10.5194/acp-2021-561

Preprint. Discussion started: 26 July 2021

(C) Author(s) 2021. CC BY 4.0 License.

(c) (i)

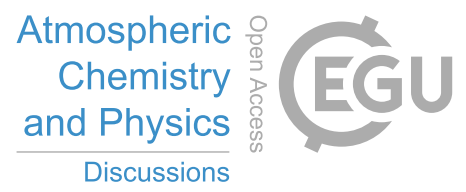

Topping, D., Barley, M., Bane, M. K., Higham, N., Aumont, B., Dingle, N., and McFiggans, G.: UManSysProp v1.0: an online and open-source facility for molecular property prediction and atmospheric aerosol calculations, Geosci. Model Dev., 9, 899-914, https://doi.org/10.5194/gmd-9-899-2016, 2016.

675 Zuend, A., Marcolli, C., Luo, B. P., and Peter, T.: A thermodynamic model of mixed organic-inorganic aerosols to predict activity coefficients, Atmos. Chem. Phys., 8, 4559-4593, https://doi.org/10.5194/acp-8-4559-2008, 2008.

Zuend, A., Marcolli, C., Booth, A. M., Lienhard, D. M., Soonsin, V., Krieger, U. K., Topping, D. O., McFiggans, G., Peter, T., and Seinfeld, J. H.: New and extended parameterization of the thermodynamic model AIOMFAC: calculation of activity coefficients for organicinorganic mixtures containing carboxyl, hydroxyl, carbonyl, ether, ester, alkenyl, alkyl, and aromatic functional groups, Atmos. Chem. Phys., 11, 9155-9206, https://doi.org/10.5194/acp-11-9155-2011, 2011. 